\title{
Medieval and Renaissance Letter Treatises and Form Letters 3: A Census of Manuscripts Found in Part of Europe. The Works on Letter Writing from the Eleventh through the Seventeenth Century Found in Albania, Austria, Bulgaria, France, Germany, and Italy. Emil J. Polak.
}

Leiden: Brill, 2015. xiv + 906 pp. \$301.

In Renaissance Quarterly 50.2, John Monfasani wrote a keen review of the first two volumes of Emil Polak's census of extant ars dictaminis and ars arengandi manuscripts. He noted the tangible utility of Polak's work and suggested some critical improvements and corrections for a future volume. Professor Monfasani also predicted that Polak's future survey of Austria, France, Germany, and Italy would add 2,000-3,000 more manuscripts to his census. He was right. There are over 2,300 manuscripts between them, bringing the worldwide total to more than 3,600 extant manuscripts. Of his suggested improvements, Polak has addressed some by providing a chapter of addenda and corrigenda, which gives information that was lacking about lost manuscripts while providing minor corrections. However, a suggested improvement of more precise running headers on the top of each page to indicate where the archives are located, not just the country, was not made. This is surprising since the holdings of large archives run for many, many pages. Another suggested improvement - getting rid of the select bibliography - was also not made. Since there are only ten new works to note from 1993 on, this is peculiar as well. Still, these are minor concerns when compared to the useful information now at hand; in this third and final volume we have a rare tool with which to begin broadly assessing the rhetorical culture of the late Middle Ages and early Renaissance.

For those scholars interested in manuscript production, there are some significant quantifiable observations to make - even adjusting for the margin of error that manuscript collections evolve uniquely and that Polak has given the readers manuscripts that date from the ninth to the nineteenth centuries. For instance, there are over 700 manuscripts in Italy and Germany each, and more than 400 each in France and Austria. If we correlate and compare the centuries of production with those manuscript totals, we see that in France there are more fourteenth-century manuscripts than fifteenth century. The opposite is true in Italy and Germany: there are vastly more fifteenth-century manuscripts than fourteenth century. These numbers are not proportional; one era does not decline or grow proportionally with respect to another. In Italy, for example, we see approximately 50 percent more fifteenth-century manuscripts than fourteenth century, but this does not hold in Germany. From this rudimentary perspective it is clear that Polak's work can be used as a starting point for evaluating how and when the artes flourished and declined.

Additionally, from Polak's detailed entries readers can assess how the artes were specifically composed. At the head of each entry Polak notes whether or not a manuscript is a combined work or a "sole work." Tallying the number of "sole-work" manuscripts 
shows that they amount to less than 25 percent of the total. Consequently, the reader notices that manuscripts with the artes are miscellaneous, often bound together with topics that range from astrology to Hebrew grammar and beyond, and that they are also often comprised of different authors. This is one of the most fascinating aspects of Polak's volume. Scholars can make their own registers of the authors found in these manuscripts. From my own census it is quite clear that the popularity of Augustino Dati's work in Italy and Germany is unrivaled, while in Austria and France Pietro della Vigna's work is unmatched - he is only bested by Dati and Gasparino Barzizza in Italy; in Germany Petrus Blesensis and Nicolaus Dybinus, on the other hand, are more popular. My census of authors reveals interesting quirks, too. In Austria, Iupiter Monoculus - who has by far the best name - is quite popular. In France, Tomaso de Capua ranks equally with Laurentius di Aquilegia, while in Germany, Stefano Fieschi di Soncino and Anthonius Haneron, among others, prove influential. Italy has favorites like Guido Faba, Petrus de Isolella, Giovanni di Bonandrea, and Antonio da Tempo beyond the many others already mentioned with respect to the other countries. The centuries in which the manuscripts were produced also reveal interesting quirks, but that is for other scholars to deal with and enlarge by incorporating the two earlier volumes to say nothing of comparing and contrasting the incipits and explicits that Polak provides for each manuscript.

Polak's broad work, unfortunately, is a type of scholarship that is slowly fading away - the type promoted by Paul Oskar Kristeller, whom Polak directly emulates. For scholars who trade in manuscript studies, his work is to be both envied and wondered at. This final volume took him at least twenty years to see through publication, and this part of the project took him to five countries and over 350 archives. One doubts whether a project of this sort could be brought to bear if it were begun today. Thankfully, it is complete, and we can now use it to our collective benefit. Let us say, then, as Professor Monfasani did many years ago: "Blessed is the scholar who leaves to future generations a work that will not be redone, but only updated."

Dustin Mengelkoch, Lake Forest College 